\title{
Civil
}

Engineering

\section{Reliability assessment of cold-formed steel beams by the FORM method}

\section{Fernanda Ferra Andrade Toledo ${ }^{1,3}$ \\ https://orcid.org/0000-0002-1988-7794 Marcilio Sousa da Rocha Freitas ${ }^{1,4}$ \\ https://orcid.org/0000-0003-4664-5368 \\ André Luis Riqueira Brandão ${ }^{2,5}$ \\ https://orcid.org/0000-0002-4857-4308}

${ }^{1}$ Universidade Federal de Ouro Preto - UFOP, Escola de Minas, Departamento de Engenharia Civil, Ouro Preto - Minas Gerais - Brasil.

${ }^{2}$ Universidade Federal de Itajubá - UNIFEI, Campus de Itabira, Instituto de Engenharias Integradas, Itabira - Minas Gerais - Brasil.

E-mails: ${ }^{3}$ ffandrade15@yahoo.com.br, 4marcilio@ufop.edu.br, ${ }^{5}$ andreriqueira@unifei.edu.br

\section{Abstract}

This article presents a procedure for the reliability assessment of cold-formed steel beams based on the Direct Strength Method (DSM) and the Effective Section Method (ESM). Using a comprehensive database, a statistical analysis of the test results was performed to determine the statistical properties of the professional factor random variable. The statistical parameters related to material strength, geometric properties and load effects were obtained from established references for reliability analysis. Safety levels compatible with the North American and the Brazilian codes relating to structural design of cold-formed steel members have been established. The first-order reliability method (FORM) was used to calculate resistance factors $\phi$ for usual nominal live-dead ratios. The results of the reliability analysis showed that the DSM and ESM design methods have similar levels of reliability. The same resistance factor as the DSM can be used for the ESM, without compromising the minimum level of reliability established. The results obtained with the LRFD calibration data, presented a good approximation with the load factor $\phi=0.90$, except for the distortional mode. With the LSD calibration data, values well below the specified were required in order to achieve the required level of reliability. It was also found that the load factor $\gamma=1.25$, in the format of the Brazilian standard, could reach the safety requirements established for all buckling modes.

Keywords: cold-formed steel, reliability index, probability distribution, bending.

\section{Introduction}

Cold-formed steel (CFS) is the usual term for steel products molded by coldworking processes performed around room temperature using a bending brake operation, press brake operation or cold roll forming. The search for increasingly light and economical structural components stimulates the use of rather slender cold-formed steel members, which are regularly susceptible to various modes of instability. As the CFS members are normally thin, and local instabilities occur before yielding of the sections. Coldformed sections are used for structural

items, such as beams, columns, joists, steel decks, and other components used in structures, i.e. residential buildings, industrial sheds and transmission towers. The United States, Mexico and Canada use the North American Specification (NAS) for the Design of Cold-Formed Steel Structural Members AISI-S100, 2016.

NAS includes design provisions for Load and Resistance Factor Design (LRFD) that is used only by the United States and Mexico, and Limit States Design (LSD), whose use is limited to

$$
\sum \gamma_{i} Q_{i} \leq \phi R_{n}
$$

The resistance factor, $\phi$, accounts for the uncertainties and variabilities inherent in the nominal resistance. The load factor, $\gamma_{i}$, accounts for the uncertainties and variabilities of the loads and load effects (Ellingwood et al., 1980).
Canada. The resistance factors for the Brazilian Code (ABNT NBR 14762, 2010) are $\gamma$ and the relationship between $\phi$ and the factor $\gamma$ is stablished as $\phi=1 / \gamma$. A limit state is represented as a condition for which a structural member, in other words, a structural system fails to perform the function that it has been designed for (Hsiao, 1989). For the limit state of strength, the usual format of the LRFD method is represented by the Equation (1). LSD and LRFD are based on the same philosophy: a design load effect less than or equal to the design capacity.

In LRFD and LSD formats, structural reliability is characterized in terms of a reliability index, $\beta$, determined by a statistical analysis of the loads and resistances. Load and resistance factors are obtained so that the reliability of a structure the nominal section properties and the minimum specified material properties. 
will be at the required target level, using the proposed normative provisions. The reliability index, $\beta$, is directly related to the load and resistance factors used in the design, and consequently, to the structural reliability of the design. The technical committee responsible for writing a design standard must calibrate the resistance factors, $\phi$, such that the reliability index, $\beta$, reaches a required target value $\beta_{0}$.

A reliability method aims to assess a reliability index or a probability of failure.
When the method is used in code calibration, reliability indexes are obtained, using a target reliability index as a reference. Several researchers have been working on formulating this calibration (Ravindra and Galambos, 1978; Ellingwood et al., 1980; Hsiao, 1989).

For the North American Specification, the resistance factor for cold-formed steel flexural members, $\phi=0.90$, was calibrated with the First Order Second Moment (FOSM) method (Hsiao,

$$
\phi=C_{\phi}\left(M_{m} F_{m} P_{m}\right) e^{-\beta_{0} \sqrt{V_{M}^{2}+V_{F}^{2}+C_{p} V_{p}^{2} V_{Q}^{2}}}
$$

$C_{\phi}=$ calibration coefficient $(1.52$ for LRFD; 1.42 for LSD)

$M_{m}=$ mean value of material factor $M$ factor $\stackrel{m}{F}$

$F_{m}^{m}=$ mean value of fabrication factor $\stackrel{m}{\mathrm{P}}$

$P_{m}=$ mean value of professional

$V_{M}=$ coefficient of variation of material factor $\mathrm{M}$

$V_{F}=$ coefficient of variation of fabrication factor $\mathrm{F}$ factor $\mathrm{P}$

$V_{P}=$ mean value of professional

$V_{Q}=$ coefficient of variation of "load effect"

$C_{p}=$ correction factor (for a large number of tests, $C_{p}$ is close to 1 )

The design basis for the LRFD and the LSD format is the same. The same

\section{Strength prediction methods}

The Direct Strength Method (DSM) was initially proposed in Schafer (2002) and has been adopted in the North American Specification as an alternative to the usual Effective Width Method (EWM) for the design of columns and beams. Local buckling behavior and buckling interaction with global buckling modes of the member's flexural, torsional, flexuraltorsional and lateral-flexural buckling can also be included in design rules by the direct methods. According to Batista resistance factor, $\phi=0.90$, given in this code shall be used to determine the available flexural strength, for both LRFD and LSD formats. However, the target values of the reliability index, $\beta_{0}$, as well as the live-to-dead load ratio may differ depending on the format of the code. Since the calibration coefficient depends mainly on the $\mathrm{Ln} / \mathrm{Dn}$ ratio and the load combination, different values are obtained for LRFD and LSD. Then, $C_{\phi}$ is 1.52 for LRFD and 1.42 for LSD.

The Brazilian code also presents Equation (2) for calculating the resistance factor, with $C_{\phi}=1.52$ (the same as the LRFD). However, the coefficient should be 1.45 or 1.42 for the load combination of the Brazilian code, $1.25 D_{n}+1.5 L_{n}$, and $L_{n} / D_{n}=5$ or $L_{n} / D_{n}=3$. It should be noted
(2010), between the two methods, DSM provides better results, when compared with experimental results. The use of the method requires calculation the crosssectional plastic resistance and the critical elastic buckling load for the buckling mode considered. For this, one of the modal approaches can be used to analyze the elastic buckling behavior: the Finite Strip Method (FSM) or the Generalised Beam Theory (GBT) method. With the help of computational resources such as the
1989). The calibration data for LRFD are the following values for the nominal live-to-dead ratio $\left(L_{n} / D_{n}\right)$, the load combinations, and the reliability index: $L_{n} / D_{n}=5,1.2 D_{n}+1.6 L_{n}, \beta_{0}=2.5$. Similarly, the LSD calibration data are: $L_{n} / D_{n}=3,1.25 D_{n}+1.5 L_{n}, \beta_{0}=3.0$.

The resistance factor may be calculated by Equation (2). Such equation, available in the North American specification, was deduced from the FOSM method.

that in previous works of calibration both North American and Brazilian codes were used the FOSM method, simpler then the FORM method.

This article shows a study of the level of reliability of CFS beam designed by the Direct Strength Method (DSM) or the Effective Section Method (ESM) available in Brazilian code. The assessment of the $\phi$ resistance factor was performed using the First Order Reliability Method (Hasofer and Lind, 1974), with LRFD and LSD calibration data. The values found were compared with the specified resistance factor, $\phi=0.90(\gamma=1.10)$. The test-to-predicted strength statistics (herein called "professional factor" $P$ ) were employed as one of the random variables of the performance function.

CUFSM $^{\circledast}$ or the $\mathrm{GBTUL}^{\odot}$, it is possible to perform the stability analysis of the profiles. Design may also be performed with direct equations of the critical buckling modes, if available. The Effective Section Method, for example, offers direct solution for bending, as described in Batista (2010).

According to NAS, DSM for symmetric sections bending about the symmetric axis considering inelastic reserve capacity for global, local and distortional buckling, can be summarized as follows:

$$
M_{D S M}=\min \left(M_{n e}, M_{n l}, M_{n d}\right)
$$

Lateral-torsional buckling:

$$
M_{n e}=\left\{\begin{array}{cl}
M_{c r e}, & M_{c r e}<0.56 M_{y} \\
\frac{10}{9} M_{y}\left(1-\frac{10 M_{y}}{36 M_{c r e}}\right), & 2.78 M_{y} \geq M_{c r e} \geq 0.56 M_{y} \\
M_{y}, & M_{c r e}>2.78 M_{y}
\end{array}\right.
$$


Local buckling:

$$
\begin{aligned}
& \lambda_{1}=\sqrt{M_{n e} / M_{c r l}}
\end{aligned}
$$

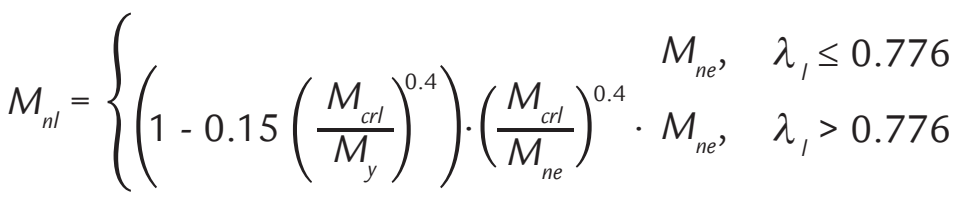

Distortional buckling:

$$
\begin{aligned}
& \lambda_{d}=\sqrt{M_{y} / M_{c r d}}
\end{aligned}
$$

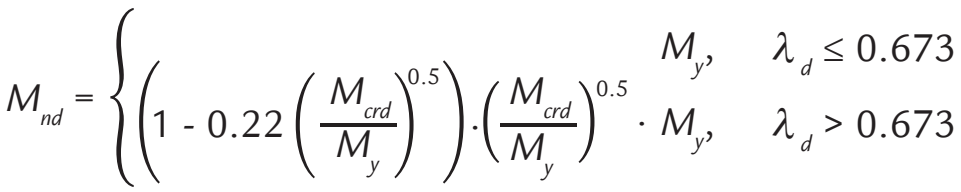

$M_{c r e}, M_{c r l}$ and $M_{c r d}$ are lateral-torsional, local and distortional critical

The ESM was conceived for the design of Cold-Formed Steel (CSF) members on the basis of the actual local buckling results of the section, together with

\section{Professional factor}

The professional factor $P$ is a random variable which represents the error in modeled resistance, and it can affect the results of the analysis. The $P$ statistics were calculated with a beam test database that was organized and the Direct Strength Method for beams was used for prediction.

From the values of the professional factor, the average of the random variable, $P_{m}$, which indicates the biased character of the theoretical model, was generated. elastic buckling moments,

$$
M_{y}=S_{f} F_{y} \text {, where } S_{f} \text { is the gross }
$$

calibrated formulations for member resistance. The strength equations were taken from the DSM. The ESM was proposed in combination with equations and tables section modulus.

that enables designers to directly access the Mcrl of usual sections. The distortional buckling was not contemplated by the ESM (Batista, 2010).
Thus, $P_{m}$, which should be unitary if the model represents exactly the studied physical phenomenon, reveals how conservative or not the model in question is, so that possible corrections are made (Brandão, 2012; Freitas et al., 2013; Freitas et al., 2018). The coefficient of variation $\left(V_{p}\right)$ is the ratio of the standard deviation to the mean. The higher the coefficient of variation, the greater the level of dispersion around the mean.
Using the results for the flexural strength of the beams, experimentally obtained by several researches, a comparison is made with the theoretical value. From this comparison, we obtain the statistical parameters, $P_{m}$ and $V_{p}$, required in this type of analysis.

The CFS beam test database, in this study, contains 138 beam tests from different experimental programs. The database references are summarized in Table 1.

Table 1 - Cold-formed steel beam test database references.

\begin{tabular}{c|c|c|c}
\hline Reference (Year) & Section Type & Predominant buckling modes & Test number \\
\hline Javaroni (1999) & Plain C, Lipped C, Lipped Z & Lateral Torsional & 13 \\
\hline Yu \& Schafer (2003) & Lipped C, Lipped Z & Local & 50 \\
\hline Yu \& Schafer (2006) & Lipped C, Lipped Z & Distortional & 48 \\
\hline Javaroni \& Gonçalves (2006) & Lipped C & Distortional & 8 \\
\hline Young \& Hancock (2006) & Plain C & Lateral Torsional & 9 \\
\hline Wang \& Young (2018) & Double Lipped C, Double Plain C & Distortional and Local & 10 \\
\hline
\end{tabular}

Mean values and standard deviations were calculated and adjusted for better probability distribution using MINITAB ${ }^{\circledR}$. The KolmogorovSmirnov adherence test was applied to verify data fit for the most com- mon distributions. Table 2 shows the statistical parameters of the variable $P$ for each group organized taking into account the buckling mode and the design method. Statistical analysis of the professional factor of the seven groups presented is available in Toledo (2019). ESM method has geometric restrictions imposed on cross sections. Sections that did not fall within the established limits were excluded from the analysis. 
Table 2 - Professional Factor statistics for DSM and ESM Method.

\begin{tabular}{|c|c|c|c|c|}
\hline \multirow{2}{*}{ Group } & \multicolumn{3}{|c|}{ P Statistics } & \multirow{2}{*}{$\begin{array}{c}\text { Probability } \\
\text { density function }\end{array}$} \\
\hline & Test Number & $\boldsymbol{P}_{m}$ & $V_{p}$ & \\
\hline DSM - All data & 138 & 1.029 & 0.123 & Lognormal \\
\hline ESM - All data & 59 & 1.150 & 0.186 & Lognormal \\
\hline DSM - Local mode & 50 & 1.051 & 0.088 & Lognormal \\
\hline ESM - Local mode & 28 & 1.080 & 0.082 & Normal \\
\hline DSM - Distortional mode & 61 & 0.988 & 0.104 & Lognormal \\
\hline DSM - Lateral Torsional Buckling (LTB) mode & 19 & 1.147 & 0.138 & Lognormal \\
\hline ESM - Lateral Torsional Buckling (LTB) mode & 19 & 1.178 & 0.159 & Lognormal \\
\hline
\end{tabular}

\section{Performance function}

The performance function, also called the failure function, is typically a function of resistance and load. The resistance of a

where $R_{n}$ is the nominal resistance based on the model used for the predicted resistance, and on the nominal properties: geometric and material. $M, F, P, D$ and $L$ are random variables representing the uncertainties in the material properties, the geometry of the cross-section, and the design assumptions, while $c^{\prime}$ is a deterministic coefficient. structural element is typically in function of the material strength, section geometry, and dimensions. In the case of gravitational

$$
g(\cdot)=R_{n} M F P-c^{\prime}(D+L)
$$

The variable $M$ is called the material factor, determined by the ratio of a tested mechanical property to a specified value. The fabrication factor $F$ is a variable, which is related for the uncertainties caused by initial imperfections, tolerances, and variations of geometric properties. The mean and coefficient of variation values were assumed in this study and loads, the loads may be expressed in function of dead and live loads. Mathematically, the failure function can be expressed by:

can be found in table "Statistics Data for determining resistance Factor" of the AISI standard (2016). The variable $P$ is the ratio between the test capacity and the predicted capacity.

For cold-formed steel member, the statistical parameters are given in Table 3. These data are based on Ellingwood et al. (1980), Hsiao (1989), and AISI (2016).

Table 3 - Statistics of load and resistance parameters.

\begin{tabular}{c|c|c|c}
\hline Load type & Mean-to-nominal value ratio & Coefficient of Variation & Distribution \\
\hline$M$ & 1.10 & 0.10 & Lognormal \\
\hline$M($ for LTB mode $)$ & 1.00 & 0.06 & Lognormal \\
\hline$F$ & 1.00 & 0.05 & Lognormal \\
\hline Dead Load $(D)$ & $D_{m} / D_{n}=1.05$ & $V_{D}=0.10$ & Normal \\
\hline Live Load $(L)$ & $L_{m} / L_{n}=1.00$ & $V_{L}=0.25$ & Type I Extreme Value \\
\hline
\end{tabular}

\section{Reliability analysis}

The calibration of the North American specification was considered, in addition to the data properly adapted to the Brazilian standard. Thus, three reliability analysis situations were defined:

(i) For AISI-LRFD: $L_{n} / D_{n}=5,1.2 D_{n}+$ $1.6 L_{n}, \beta_{0}=2.5$;

(ii) For AISI-LSD: $L_{n} / D_{n}=3,1.25 D_{n}+$ $1.5 \mathrm{Ln}, \beta_{0}=3.0$;

(iii) For ABNT NBR 14762, 2010): $L_{n} / D_{n}=5,1.25 D_{n}+1.5 L_{n}, \beta_{0}=2.5$.

The data groups were defined according to Table 2 . Figure 1 shows a graph with the results of the load factors calculated with the First Order Reliability
Method (FORM).

Using all available data during the statistical analysis of the professional factor, it was found that results were similar for DSM and ESM. While the resistance factor calculated for the LRFD $(\phi=0.87)$ approached the specified value, the calculated resistance factor $(\phi=0.73)$ for the LSD was so far from that specified. With the calibration data of the Brazilian standard, the calculated resistance factor was $\phi=0.85$, which in the Brazilian standard is equivalent to the $\gamma=1.18$ approximately. The Brazilian standard establishes a resistance factor of 1.10 , here treated as being equivalent to $\phi=0.90$.

With the use of data from the professional factor related to the local buckling mode, the results found between the DSM and the ESM were used for statistical analysis of the professional factor. In this case, the resistance factors raised to $\phi=0.90$ for the LRFD. For the Brazilian standard there was a good convergence with the specified value. The LSD results stand out for requiring a significant reduction in the resistance factor with $\phi$ being assessed at 0.78 (DSM) and 0.80 (ESM) so that the required safety level is achieved.

The resistance factors obtained for 
the distortional buckling were slightly below the other analyses. The lateral torsional buckling (LTB) mode showed exactly the same level of safety for DSM and ESM design methods. In the case of the LRDF format, the resistance factor converged to 0.90 when the target index of 2.50 was used. For the Brazilian standard, the calculated $\phi$ factor was 0.85 for the same target reliability index. For the LSD format, the calculated resistance factor was 0.75 when $\beta_{0}=3.0$.

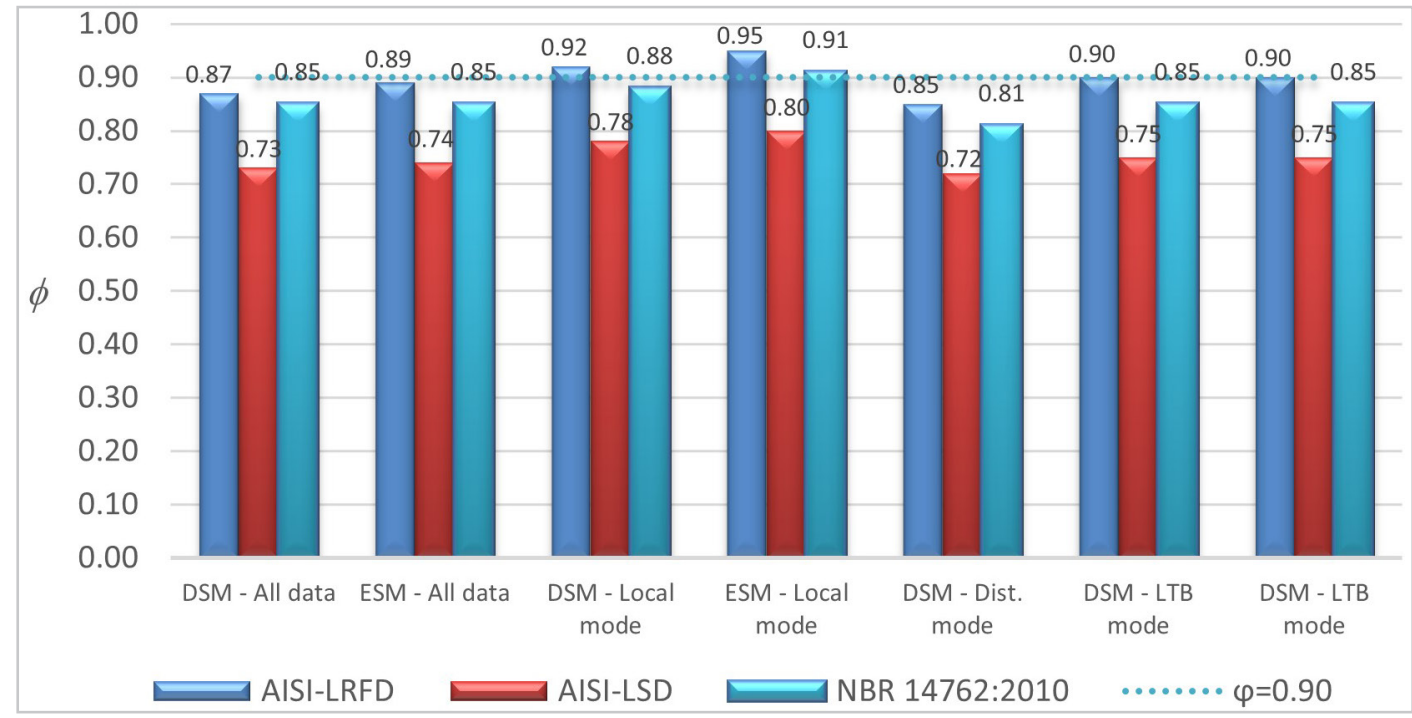

Figure 1 - Reliability indexes for DSM and ESM.

\section{Conclusions}

This article presented a procedure to assess the safety of cold-formed steel flexural members designed according to DSM and ESM. In the case of structural members, a design method is considered reliable if the calculated reliability index is greater than the target reliability index of 2.5 using the LRFD or 3.0 for LSD. Thus, the resistance factors for beams were calculated using an FORM method approach and the study covered seven groups of statistical data, combining three buckling modes and two design methods.

The discrepancy between the LRFD and LSD formats should not be neglected. Since they are part of the same standard code, but use different calibration data, the resistance factors should be different. In the case of adopting the same resistance factor for both formats, the smallest factor would be the most appropriate choice.

The differences observed in the comparison between the local and global buckling modes, indicate the possibility of codes adopting a different resistance factor for each mode. For example, to adopt $\phi=0.85$ for the distortional mode and $\phi=0.90$ for the local mode, considering the LRFD format.

For the local mode, similar resistance factors are reached for both the DSM and ESM design methods. The lateral torsional buckling (LTB) mode showed the same level of safety for both
DSM and ESM design methods. In the case of the LRDF format, a resistance factor $\phi=0.90$ is recommended.

The results with the calibration data stipulated for the NBR were lower than those for the LRFD. The difference in these results, although small, is due to the fact that the load combinations used are not the same. The $\gamma$ factor of 1.10 (equivalent to $\phi=0.90$ ) used in the Brazilian standard reaches the target reliability index in situations involving the local mode. Considering the lowest resistance factor $(\phi=0.81)$ obtained for the distortional mode, a $\gamma=1.25$ could meet all situations similar to the cases analyzed in this study.

\section{Acknowledgements}

The authors are grateful to UFOP (Universidade Federal de Ouro Preto) and CAPES (Coordenação de Aperfeiçoamento de Pessoal de Nível Supe- rior) for supporting the development of this work.

\section{References}

AMERICAN IRON AND STEEL INSTITUTE. AISI-S100-16: North American specification for the design of cold-formed steel structural members. Washington, D.C.: ANSI/AISI, 2016.

ASSOCIAÇÃO BRASILEIRA DE NORMAS TÉCNICAS. ABNT NBR 14762: Dimensionamento de estruturas de aço constituídas por perfis formados a frio - Procedimento. Rio de Janeiro: ABNT, 2010.

BATISTA, E. M. Effective section method: a general direct method for the design of steel cold-formed members under local-global buckling interaction. Thin-Walled Structures, v.48, p. 345-356, 2010.

BEBIANO, R.; PINA, P.; SILVESTRE, N.; CAMOTIM, D. GBTUL - Buckling and vibration analysis of thin-walled members. Version: 2.0.4.4. Lisboa: Generalised Beam Theory Group, Instituto Superior Técnico, University of Lisbon, Portugal, 2013. Available at: www.civil.ist.utl.pt/gbt. 
BRANDÃO, A. L. R. Calibração de coeficiente de ponderação da resistência em barras e ligações de perfis formados a frio. 2012. 227 f. Tese (Doutorado em Engenharia Civil) - Escola de Minas, Universidade Federal de Ouro Preto, Ouro Preto, 2012.

ELLINGWOOD, B.; MACGREGOR, J. G.; GALAMBOS, T. V.; CORNELL, C. A. Development of a probability-based load criterion for American National Standard A58. Washington, D.C: National Bureau of Standards, United States Department of Commerce, 1980. (NBS Special Publication, 577).

FREITAS, M. S. R.; BRANDÃO, A. L. R.; FREITAS, A. M. S. Resistance factor calibration for cold-formed steel compression members. REM: Revista Escola de Minas, v. 66, n. 2, p.233-238, 2013.

FREITAS, M. S. R.; BRANDÃO, A. L. R.; ALVES, A. R. Reliability analysis of welded and bolted connections in cold-formed steel sections. REM - International Engineering Journal, Ouro Preto, v. 71, n. 3, p. 371-376, 2018.

HASOFER, A. M.; LIND, N. C. Exact and invariant second moment code format. Journal of the Engineering Mechanics Division, v. 100, n. EM1, p111-121, 1974.

HSIAO, L. E. Reliability based criteria for cold-formed steel members. 1989. 289 f. Thesis (Ph. D. in Civil Engineering) - University of Missouri, Rolla, 1989.

JAVARONI, C. E. Perfis de aço formados a frio submetidos à flexão: Análise teórico-experimental. 1999. $204 \mathrm{f}$. Tese (Doutorado em Engenharia Civil) - Escola de Engenharia de São Carlos, Universidade de São Paulo, São Carlos, 1999.

JAVARONI, C. E; GONÇALVES, R. M. Distortional buckling of simple lipped channel in bending. In: INTERNATIONAL SPECIALTY CONFERENCE ON COLD-FORMED STEEL STRUCTURES, 18th, 2006, Orlando, Florida. Proceedings [...]. [S. l.]: Scholars' Mine, 2006.

LI, Z.; SCHAFER, B. W. CUFSM ${ }^{\circledast}$ Version: 4.03. [S. 1.: s. n.], 2010. Available at: https://www.ce.jhu.edu/bschafer/cufsm/.

MINITAB. MINITAB ${ }^{\circledR}$ : Version: 18.1. Available at: http://www.minitab.com/pt-br/

RAVINDRA, M. K.; GALAMBOS, T. V. Load and resistance factor design for steel. Journal of the Structural Division, v.104, n.9, p.1337-1353, 1978.

SCHAFER, B. W. Local, distortional and Euler buckling in thin-walled columns, Journal of Structural Engineering, v. 128, n. 3, p. 289-299, 2002.

TOLEDO, F. F. A. Obtenção do índice de confiabilidade de barras de perfis formados a frio submetidas à flexão simples com o emprego do método FORM. 2019. 115 f. Dissertação (Mestrado Profissional em Construção Metálica) - Escola de Minas, Universidade Federal de Ouro Preto, Ouro Preto, 2019.

WANG, L.; YOUNG, B. Behaviour and design of cold-formed steel built-up section beams with different screw arrangements. Thin-Walled Structures, v.131, p. 165-32, 2018.

YOUNG, B.; HANCOCK, G. J. Section moment capacity of cold-formed unlipped channels. Advances in Steel Structures, v. 1, p.349-356, 1999.

YU, C.; SCHAFER, B. W. Distortional buckling tests on cold-formed steel beams. Journal of structural engineering, v. 132, n.4, p. 515-528, 2006.

YU, C.; SCHAFER, B. W. Local buckling tests on cold-formed steel beams. Journal of structural engineering, v. 129, n.12, p. 1596-1606, 2003.

Received: 5 May 2020 - Accepted: 19 January 2021.

All content of the journal, except where identified, is licensed under a Creative Commons attribution-type BY. 